CASE REPORT

\title{
Late pulmonary artery stump thrombosis with post embolic pulmonary hypertension after pneumonectomy
}

\author{
P A Thomas, C Doddoli, F Barlési, M Reynaud-Gaubert, R Giudicelli, P Fuentes
}

Thorax 2006;61:177-178. doi: 10.1136/thx.2004.028480

Ten years after right pneumonectomy for primary lung cancer, a 51 year old man developed a pulmonary artery stump thrombosis which produced microemboli in the remaining lung and, in turn, led to chronic pulmonary hypertension. This case strongly suggests that prolonged postoperative thromboembolic prophylaxis should be considered in patients undergoing right pneumonectomy.

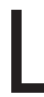
ate dyspnoea following pneumonectomy is usually due to progressive disease of the remaining lung, post pneumo-nectomy syndrome from distortion of the remaining main bronchus, and sometimes reopening of the foramen ovale. We report a patient in whom chronic embolisation originating from a pulmonary artery stump thrombosis occurred 10 years after pneumonectomy and led to the development of severe pulmonary hypertension.

\section{CASE REPORT}

A 51 year old man underwent right pneumonectomy in April 1993 for lung cancer with a satisfactory postoperative course. In November 2002 he complained of asthenia and back pain so a chest CT scan was performed which ruled out recurrence of the cancer. The patient's condition deteriorated with progressive dyspnoea. In February 2003 arterial blood gas analysis at room air showed mild hypoxia $\left(\mathrm{PaO}_{2} 9.7 \mathrm{kPa}\right)$ and hypocapnia $\left(\mathrm{PaCO}_{2} 4 \mathrm{kPa}\right)$. Spirometric findings were as follows: total lung capacity $3.75 \mathrm{l}$ ( $58 \%$ of predicted), forced expiratory volume in 1 second $1.57 \mathrm{l}$ (55\% of predicted), forced vital capacity 2.12 l (59\% of predicted), and carbon monoxide transfer coefficient $3.51 \mathrm{ml} / \mathrm{min} / \mathrm{kPa} / \mathrm{l}(71 \%$ of predicted). The electrocardiogram showed sinus tachycardia and right axis deviation and transthoracic echocardiography showed right ventricular dilatation and third degree tricuspid regurgitation with systolic pulmonary artery pressure (PAP) estimated at $85 \mathrm{~mm} \mathrm{Hg}$. Venous ultrasonography ruled out acute deep venous thrombosis of the lower extremity. Infused spiral CT scanning revealed an endoluminal filling defect in the right pulmonary artery stump that had not been present 3 months earlier (fig lA). The findings on a transverse thin section CT scan (fig $1 \mathrm{~B}$ ) and lung perfusion scan using ${ }^{99 \mathrm{~m}} \mathrm{Tc}$ macroaggregated serum albumin (fig $\mathrm{IC}$ ) were concordant with the diagnosis of chronic thromboembolic disease.

Treatment with subcutaneous calcium heparin was started and relayed by oral vitamin $\mathrm{K}$ antagonist (fluinidione) to an INR of 2.5. Calcium channel blockers (diltiazem chlorhydrate $180 \mathrm{mg} /$ day) combined with diuretics (furosemide $40 \mathrm{mg} /$ day) were given. The patient was still alive 12 months later, free of cancer, but with increased breathlessness on exertion. At hospital readmission, blood gases at rest revealed hypoxaemia $\left(\mathrm{PaO}_{2} 8.6 \mathrm{kPa}, \mathrm{PaCO}_{2} 4 \mathrm{kPa}, \mathrm{pH} 7.42\right)$. The 6 minute walk test had to be interrupted after a distance of 240 metres because of increased dyspnoea, blood oxygen desaturation (83\%), and chest pain. Cardiac catheterisation confirmed worsening of the pulmonary hypertension with the following haemodynamics: mean right atrial pressure $14 \mathrm{~mm} \mathrm{Hg}$, systolic PAP $96 \mathrm{~mm} \mathrm{Hg}$, mean PAP $56 \mathrm{~mm} \mathrm{Hg}$, pulmonary artery occlusion pressure $5 \mathrm{~mm} \mathrm{Hg}$, cardiac output $3.8 \mathrm{l} / \mathrm{min}$, total pulmonary resistance 13.4 Wood units, absence of shunt, and no significant acute response to inhaled nitric oxide.

\section{DISCUSSION}

Ziomek and colleagues ${ }^{1}$ reported prospectively an incidence of postoperative thromboembolic disease of $19.5 \%$ after thoracotomy without specific prophylaxis, with thromboembolism more common after surgery for malignant disease. Perioperative heparinisation reduces but does not remove the risk. $^{2}$ Pulmonary embolism usually occurs in the early postoperative period and does not necessarily originate from the deep veins of the lower extremity. Patients can develop thrombi in the superior vena caval system and/or the right cardiac cavities, especially in the presence of chronic $\operatorname{arrhythmia}^{3}$ or when extended resections requiring the use of prosthetic materials have been performed. ${ }^{4}$ Patients can also develop thrombi in the pulmonary artery stump after pneumonectomy that may or may not embolise to the remaining lung.

Pulmonary artery stump thrombosis may be identified as an incidental finding on follow up CT scans to detect disease recurrence. ${ }^{5}$ Microemboli may respond to treatment if appropriately and promptly diagnosed. In contrast, massive embolisation is usually lethal due to the single lung status, whatever the initial location of the clot might have been, with anecdotal success after anticoagulants and/or thrombolysis or embolectomy. ${ }^{\circ}$

Forty years ago Chuang et $a l^{7}$ showed that patients undergoing right pneumonectomy were more likely to experience pulmonary artery stump thrombosis. This is believed to be due to anatomical features; the right arterial stump is commonly longer than the left one ${ }^{8}$ which results in turbulence in the main trunk and stasis of blood in the stump, both rheological factors triggering thrombus formation. As a consequence, it would be expected that minimising the size of the arterial stump would prevent such a complication. Unfortunately, Arcinegas and Coates failed to confirm this hypothesis, ${ }^{9}$ and also found that the thrombosis may continue enlarging until it completely obstructs outflow from the right ventricle.

Obviously, long term survivors after pneumonectomy are rare because the indications for such an operation are dominated by advanced stage thoracic malignancies. As a consequence, only a few studies have addressed the haemodynamic changes that occur after pneumonectomy. Despite the reduction by half of the pulmonary vasculature, there is usually no significant change postoperatively compared with preoperative systolic PAP, pulmonary vascular resistance index, central venous pressure, cardiac index, and 

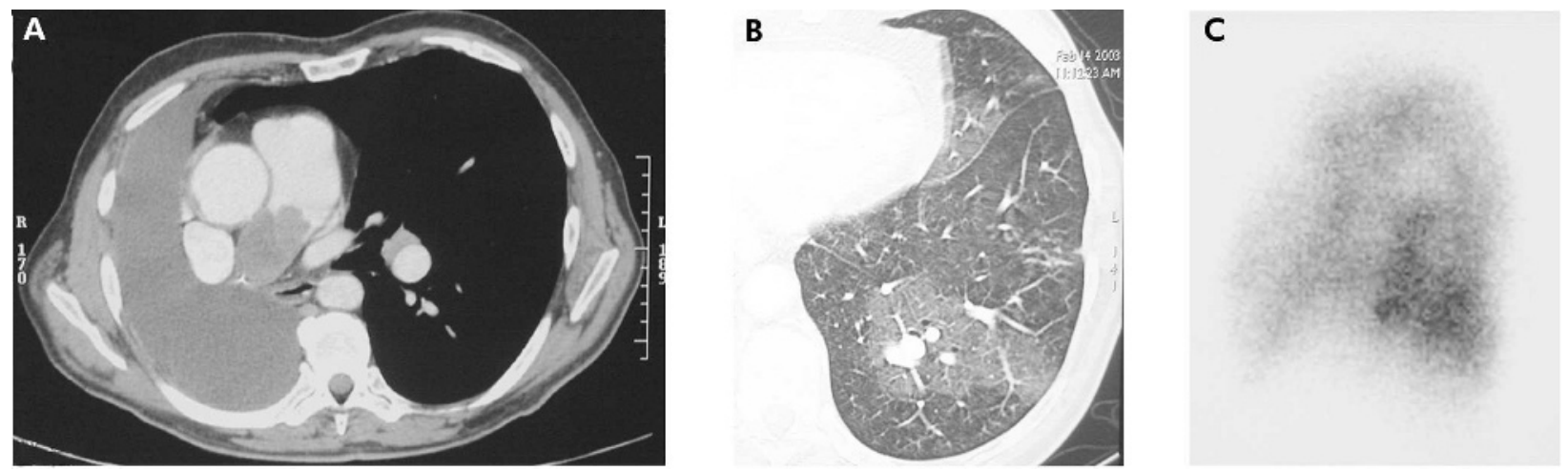

Figure 1 (A) Spiral CT scan after right pneumonectomy showing an endoluminal filling defect in the right pulmonary artery stump and the absence of additional thrombi in subsegmental branch arteries. (B) Transverse thin section CT scan showing multiple dilated vessels in the left lower lobe and

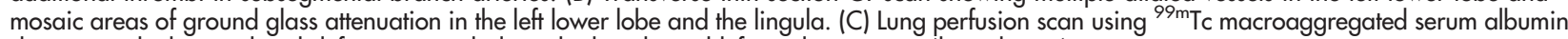
showing multiple peripheral defects, particularly in the lingula and left Fowler segment (lateral view).

pulmonary capillary wedge pressure. ${ }^{10}$ Our patient's history suggests that the late onset of cor pulmonale may be attributed to chronic embolisation and remodelling of the pulmonary vascular bed. While it is more common in the immediate postoperative period, thromboembolic disease has been suspected but seldom reported as a long term complication following standard pneumonectomy. To the best of our knowledge, a 10 year delay between such a complication and the initial surgery has not previously been reported.

This case supports the liberal use of CT scanning in the follow up of pneumonectomised patients. It also strongly suggests that prolonged postoperative thromboembolic prophylaxis in patients undergoing pneumonectomy should be recommended. Finally, it highlights the limitations of currently available treatments for post embolic pulmonary hypertension.

\section{Authors' affiliations}

P A Thomas, C Doddoli, R Giudicelli, P Fuentes, Department of Thoracic Surgery, Sainte Marguerite University Hospital, Marseille, France

P A Thomas, C Doddoli, UPRES 2201, University of the Mediterranean, Marseille, France

F Barlesi, Department of Thoracic Oncology, Sainte Marguerite University Hospital, Marseille, France

M Reynaud-Gaubert, Department of Respiratory Diseases, Sainte Marguerite University Hospital, Marseille, France; and UPRES 3287, University of the Mediterranean, Marseille, France
Competing interests: none declared.

Correspondence to: Dr P A Thomas, Service de Chirurgie Thoracique, Hôpital Sainte Marguerite, 274 Bvd Ste Marguerite, 13274 Marseille, Cédex 09, France; pathomas@ap-hm.fr

Received 16 May 2004

Accepted 28 August 2004

\section{REFERENCES}

1 Ziomek S, Read RC, Tobler HG, et al. Thromboembolism in patients undergoing thoracotomy. Ann Thorac Surg 1993;56:223-7.

2 Kalweit G, Huwer $\mathrm{H}$, Volkmer I, et al. Pulmonary embolism: a frequent cause of acute fatality after lung resection. Eur J Cardiothorac Surg 1996;10:242-6.

3 Krowka MJ, Pairolero PC, Trastek VF, et al. Cardiac dysrhythmia following pneumonectomy. Clinical correlates and prognostic significance. Chest 1987:91:490-5.

4 Thomas $\mathbf{P}$, Magnan PE, Moulin G, et al. Extended operation for lung cancer invading the superior vena cava. Eur J Cardiothorac Surg 1994;8:177-82.

5 Wechsler RJ, Salazar AM, Gessner AJ, et al. CT of in situ vascular stump thrombosis after pulmonary resection for cancer. AJR Am J Roentgenol 2001;176:1423-5.

6 Chen Q, Tang ATM, Tsang GM. Acute pulmonary thromboembolism complicating pneumonectomy: successful operative management. Eur J Cardiothorac Surg 2001;19:223-5.

7 Chuang TH, Dooling JA, Connolly JM, et al. Pulmonary embolization from vascular stump thrombosis following pneumonectomy. Ann Thorac Surg 1966;2:290-8.

8 Schiller VL, Gray RK. Causes of clot in the pulmonary artery after pneumonectomy. AJR Am J Roentgenol 1994;163:745-6.

9 Arciniegas E, Coates EO. Massive pulmonary arterial thrombosis following pneumonectomy. J Thorac Cardiovasc Surg 1971;61:487-9.

10 Kopec SE, Irwin RS, Umali-Torres CB, et al. The postpneumonectomy state. Chest 1998; 114:1158-84. 